\title{
Nutritional Deficiencies and Neglected Tropical Disease
}

\section{Guilherme Malafaia*}

Department of Biological Sciences, Instituto de Educação, Ciência e Tecnologia Goiano - Câmpus Urutaí, Brazil. Researcher at Núcleo de Pesquisasem Ciências Biológicas e Ambientais, Goiás, Brazil

"Corresponding author: Guilherme Malafaia, Department of Biological Sciences, Instituto de Educação, Ciênciae TecnologiaGoiano - CâmpusUrutaí, Brazil. Researcher at Núcleo de Pesquisasem Ciências Biológicas e Ambientais, Goiás, Brazil. E-mail: guilhermeifgoiano@gmail.com

Received date: Dec 03, 2014, Accepted date: Jan 09, 2015, Published date: Jan 16, 2015

Copyright: (c) 2015 Guilherme Malafaia. This is an open-access article distributed under the terms of the Creative Commons Attribution License, which permits unrestricted use, distribution, and reproduction in any medium, provided the original author and source are credited.

\section{Introduction}

In tropical countries, neglected diseases represent a group of infectious diseases that predominantly affects the poor and vulnerable populations and contributes to the perpetuation of the cycle of poverty, inequality and social exclusion, mainly due to its impact on child health in reduced productivity of the working population and the promotion of social stigma [1]. In the context of the populations, these diseases are feared and constitute a source of social stigma and prejudice, making them usually hidden and poorly documented. In many countries, such as Brazil, these diseases tend to be omitted in panoramas control of health services, given that affect populations that are typically marginalized and low political visibility. Already internationally, due to the fact that tropical diseases are usually linked to geographic and environmental conditions, does not constitute a threat of a worldwide pandemic, a fact that makes economic market linked to these diseases a field unattractive.

As a result, such diseases have been progressively marginalized by those responsible for the research programs of both the public and private sectors, mainly because the large portion of the population affected by these diseases is poor and does not offer a profitable return enough for pharmaceutical companies to invest in research and developing new drugs for their treatment.

An important factor that contributes to the worsening of the people with neglected infectious disease it is nutritional status. It is known that the nutritional status of the patient is one of a key modulator of the immune response, which on the one hand, an important determinant of risk and prognosis of infectious diseases and, secondly, directly influenced by infection [2]. For some time, researchers such as Gordon [3] has warned that the synergistic interaction pattern, where a worse nutritional status contributes negatively to the development and evolution of infection, as the infection worsens nutritional status is a phenomenon crucial for understanding the population dynamics of infection and to establish strategies to control these diseases.

However, much remains to be investigated, especially when considering the existence of gaps related to biological mechanisms of interaction between infection and various nutritional deficiencies, both macro and micronutrients. As an example we can mention the state of art related to leishmaniasis and Chagas disease and its relationship with nutritional status. As discussed by Fenwick [4], Chagas disease and leishmaniasis are included in the group of the most neglected tropical diseases in the world. The Chagas disease is caused by the parasite Trypanosomacruzi and affects approximately 10 million individuals throughout Latin America [5,6]. Regarding leishmaniasis (group of diseases ranging from cutaneous lesions to fatal visceral infections and systemic), it is estimated that there are currently 12 million people infected worldwide at least 88 countries [7].
Regarding leishmaniasis, is suggested that host nutritional status is important when studying the visceral leishmaniasis (VL) and that adequate nutrition of the population is an important form of protection against the emergence of new pathogens, being necessary future research on the prevalence of PEM, especially in VL endemic areas [8]. Furthermore, studies are required to analyze the specific impacts of malnutrition or nutritional deficiencies on elements of the immune system involved in immune response to L. chagasi (syn. L. infantum) or L. donovani infection. Few studies investigated, specifically, the relation between malnutrition and VL. Thus, many questions still remain without definitive answers, such as: How does malnutrition affect VL epidemiology and distribution? How does malnutrition affect VL diagnosis and treatment? How should manage $\mathrm{VL} /$ malnutrition cases? Similarly, for example, is it possible to reduce the risk of $\mathrm{VL}$ in malnutrition cases? If so, how? Understanding the immune mechanisms involved in relation malnutrition and VL may lead to new prophylactic and therapeutic strategies to stop the impaired responses to Leishmania ssp. and other adverse effects of malnutrition in millions of people.

More recently showed the close relationship between Chagas disease and nutritional deficiency [9]. We discussed about few evidences of nutritional deficiencies (protein-energy malnutrition and micronutrient malnutrition) and their effects on T. cruzi infection. In this way, protein deficiency was shown to delay recovery of noradrenaline levels that normally occurs during chronic phase of experimental Chagas disease. Besides, this protein deficiency also decreases resistance to infection and fails to control parasite replication. Deficiencies in iron and vitamins A, E, B1, B5, and B6 also exacerbated $\mathrm{T}$. cruzi infection in experimental models showing correlations between severity and progression of the disease. Despite this new evidence about nutritional deficiencies and host immune response against protozoan, few studies have been developed about the T. cruzi infection.

The VL and Chagas disease are examples that show that many studies still need to be developed. Similar scenario can be observed for other neglected tropical diseases such as malaria, dengue, schistosomiasis, tuberculosis, among others. In this context, this special issue entitled "Vitamin Deficiencies or Trace Elements and Infectious Diseases" constitutes an important vehicle that can contribute enormously to elucidate biological mechanisms involved in the relationship "nutritional deficiency and infectious diseases.

\section{References}

1. Montresor A, Gabrielli AF, Chitsulo L, Ichimori K, Mariotti S, et al. (2012) Preventive chemotherapy and the fight against neglected tropical diseases. Expert Rev Anti Infect Ther 10: 237-242. 
Citation: Malafaia G (2015) Nutritional Deficiencies and Neglected Tropical Disease. Biol syst Open Access 4: 126. doi: 10.4172/2329-6577.1000126

Page 2 of 2

2. Scrimshaw NS, SanGiovanni JP (1997) Synergism of nutrition, infection and immunity: an overview. Am J ClinNutr 66: 464S-477S.

3. Gordon JE. Synergism of malnutrition and infectious disease. In: Beaton GH, Bengoa JM, editors. Nutrition in preventive medicine. Geneva: WHO; 1976. p. 193-209.

4. Fenwick A (2012) The global burden of neglected tropical diseases. Public Health 126: 233-236.

5. Bern C, Martin DL, Gilman RH (2011) Acute and congenital Chagas disease. AdvParasitol 75: 19-47.
6. Hotez PJ, Dumonteil E, Woc-Colburn L, Serpa JA, Bezek S, et al. (2012) Chagas disease: "the new HIV/AIDS of the Americas". PLoSNegl Trop Dis 6: e1498.

7. Kedzierski L (2011) Leishmaniasis. Hum Vaccin 7: 1204-1214.

8. Malafaia G (2009) Protein-energy malnutrition as a risk factor for visceral leishmaniasis: a review. Parasite Immunol 31: 587-596.

9. Malafaia G, Talvani A (2011) Nutritional Status Driving Infection by Trypanosomacruzi: Lessons from Experimental Animals. J Trop Med 2011: 981879. 